\title{
Frontal and glabellar myotomy: single short frontal scar approach
}

\author{
Miotomia frontoglabelar: acesso por pequena incisão frontal
}

Rogério Schutzler Gomes ${ }^{1}$

Study conducted at Beiramar Plastic Surgery Clinic,

Florianópolis, SC, Brazil.

Submitted to SGP (Sistema de Gestão de Publicações/Manager Publications System) of RBCP (Revista Brasileira de Cirurgia

Plástica/Brazilian Journal of Plastic Surgery).

Received: January 22, 2011 Accepted: August 9, 2011

\begin{abstract}
Background: Frontal and glabellar muscle hyperactivity with consequent wrinkles are frequent complaints in plastic surgery. Treatment consists of impediment of related muscles; this can be achieved by application of botulinum toxin or surgery by means of classic coronal incision, endoscopic approach, transblepharoplasty access, or non-endoscopic limited approaches. This paper proposes an alternative of limited approach in which an incision is made on the central frontal scalp for treatment of the frontal and glabellar muscles. Methods: Between March 2009 and April 2010, 20 female patients were treated using a small incision on the frontal scalp, followed by dissection of frontal and glabellar regions. Muscles and supratrochlear and supraorbital nerve branches were identified; subsequently, frontal and glabellar muscle myotomy was performed. Results: All patients showed good results by frontal and glabellar muscle impediment during the evaluation period, with improvement in wrinkles and hyperactivity. Complications consisted of temporary paresthesia and pruritus in the central frontal region and scalp, in addition to recurrence of partial muscle contraction. Conclusions: The small incision approach on the central frontal scalp for treatment of frontal and glabellar muscles seems to be a good alternative to other surgical options due to its small size, inconspicuous scarring, and direct visualization of frontal and glabellar anatomic structures, allowing selective myotomy or myectomy.
\end{abstract}

Descriptors: Rhytidoplasty. Esthetics. Plastic surgery/methods. Face/surgery.

\section{RESUMO}

Introdução: A hiperatividade da musculatura frontoglabelar, com suas consequentes rugas, são queixas frequentes em consultórios de cirurgia plástica. $O$ tratamento consiste de impedimento desses músculos, o que pode ser obtido com a aplicação de toxina botulínica ou cirurgicamente, por incisão coronal clássica, acesso endoscópico, acesso transblefaroplastia ou acessos limitados não-endoscópicos. Neste artigo é proposta uma alternativa de acesso limitado, por incisão pós-capilar central frontal (IPCF), para tratamento das musculaturas frontal e glabelar. Método: Entre março de 2009 e abril de 2010, 20 pacientes do sexo feminino foram submetidas a IPCF, seguida de dissecção das regiões frontal e glabelar. Os músculos e os nervos supratroclear e supraorbitário foram identificados, sendo, em seguida, realizada miotomia dos músculos frontoglabelares. Resultados: Todos os casos apresentaram bons resultados pelo impedimento da musculatura frontoglabelar no período avaliado, com melhora das rugas e da hiperatividade. As complicações observadas foram temporárias e incluíram parestesia e prurido na região frontal central e no escalpe, além de recorrência parcial da contração muscular. Conclusões: A IPCF parece ser uma boa alternativa para o tratamento das musculaturas frontal e glabelar, pela pequena incisão, pela cicatriz inaparente e por permitir visão direta das estruturas anatômicas das regiões frontal e glabelar, permitindo miotomia ou miectomia seletiva.

Descritores: Ritidoplastia. Estética. Cirurgia plástica/métodos. Face/cirurgia.

1. Plastic surgeon, full member of the Brazilian Society of Plastic Surgery and director of Clínica Beiramar Cirurgia Plástica, Florianópolis, SC, Brazil. 


\section{INTRODUCTION}

Hyperactivity of frontal and glabellar muscles and the consequent wrinkles are frequent complaints in plastic surgery offices ${ }^{1}$.

Muscles related to hyperactivity and wrinkles are the frontal, corrugator supercilii (with its horizontal and oblique portions), depressor supercilii, procerus, and medial portion of orbital fibers of the orbicularis oculi muscle ${ }^{2}$. Treatment consists of impediment of muscle structures responsible for wrinkles or hyperactivity. This effect can be chemically induced through intramuscular injection of botulinum toxin ${ }^{3,4}$ with temporary effects (4-6 months), or surgically induced by myotomy or myectomy via a classical bicoronal incision ${ }^{5,6}$, endoscopic approach ${ }^{7-12}$, transblepharoplasty ${ }^{13,14}$, and nonendoscopic limited approaches ${ }^{15,16}$.

This paper aims to describe the use of a limited surgical approach to the frontal and glabellar regions via a small incision on the central frontal scalp, and to compare this procedure with surgical options described in the literature reviewed.

\section{METHODS}

Between March 2009 and April 2010, 20 female patients underwent surgery due to complaints of muscle hyperactivity. Complaints involved both frontal and glabellar wrinkles and moderate and well-defined frontal glabellar wrinkles, classified as 3,4 , and 5 degrees according to the classification of Lemperle et al. ${ }^{17}$ during rhytidoplasty ( 18 cases; 2 cases in isolated procedures). The patients were prepared by marking the frontal and glabellar wrinkles visible under forced expression.

Patients underwent local anesthesia $(30 \mathrm{ml}$ of $0.3 \%$ lidocaine and 1:290,000 epinephrine) and sedation. The procedure began at least 15 minutes after local infiltration in order to enable vasoconstriction.

A 3-cm horizontal incision was made at $1 \mathrm{~cm}$ to $1.5 \mathrm{~cm}$ behind the hair implantation line, parallel to hair follicle inclination (Figure 1). Subgaleal dissection was performed using scissors and a specific dissector, going up to the superior orbital rim and the glabellar region guided by preoperative marking (Figure 2).

The supraorbital nerve was identified and preserved with the aid of cold light, under direct visualization (Figure 3).

The electrocautery probe was angled to follow the frontal bone contour, with the tip directed upwards (Figure 4).

Myotomy was performed under the guidance of preoperative markings, preserving the supraorbital and supratrochlear innervation, and preferably carried out using scissors (dilatation and section) and complementation with electrocautery (section and coagulation).

In selected cases, lateral fibers of the frontal muscle were deliberately preserved in order to raise the eyebrow edge.

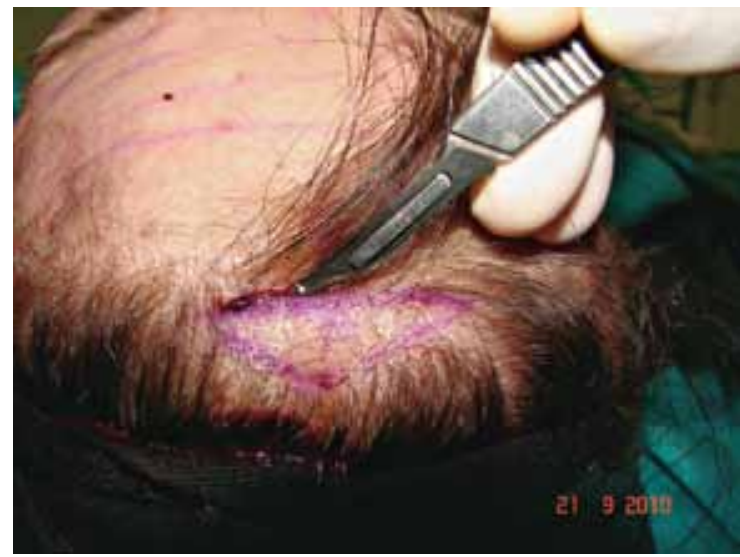

Figure 1 - Incision parallel to orientation of hair follicles.
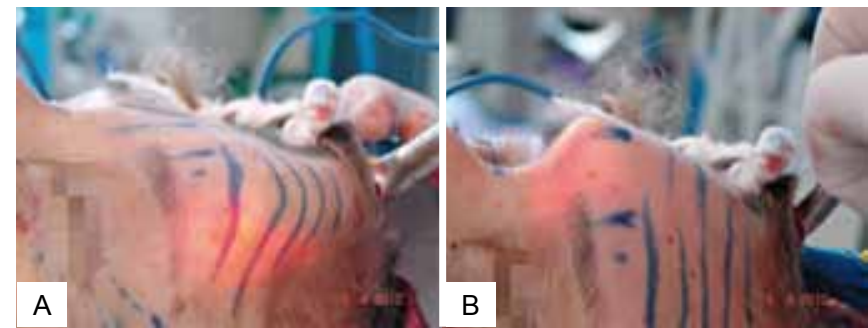

Figure 2 - In A, subgaleal dissection: lateral and lower edges. In $\boldsymbol{B}$, subgaleal dissection: medial and lower edges in the glabellar region.

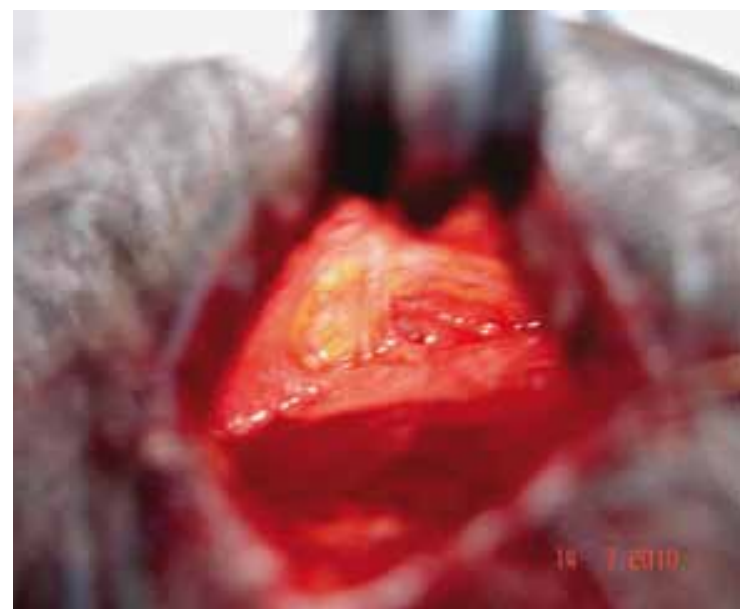

Figure 3 - Supraorbital vessels and nerves identified and preserved.

The corrugator supercilii muscles were dissected and isolated using scissors, and were medially and laterally myotomized in relation to the supraorbital nerve using an electrocautery instrument (Figure 5). A horizontal myotomy was medially performed in relation to both supratrochlear nerves, by divulsion with scissors and complementation with cautery for the procerus and depressor supercilii muscles. 


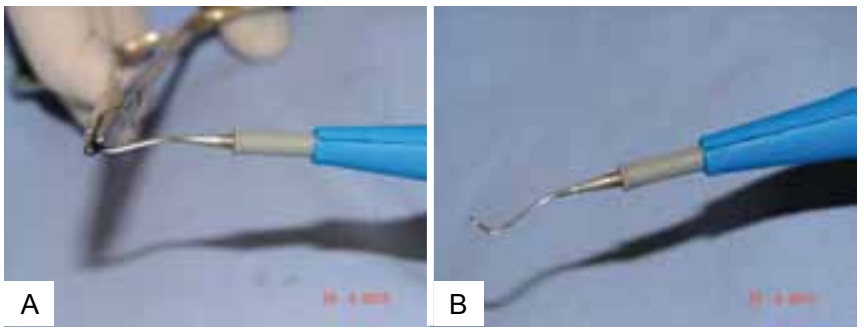

Figure 4 - In A, calibration of the cautery tip with needle holder in accordance with the frontal curvature, and extremity prepared for myotomy. In $\boldsymbol{B}$, calibration of the cautery tip: final angulation.

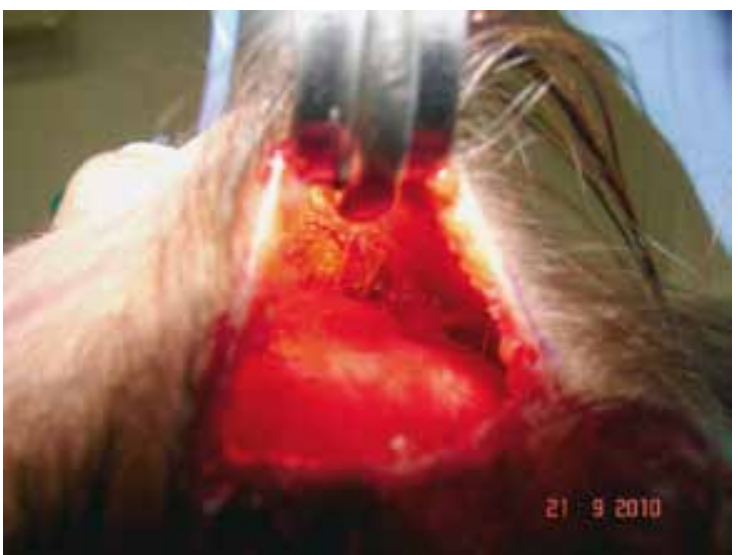

Figure 5 - Frontal myotomy performed with nerve preservation.

Hemostasis was reviewed, and a total skin ellipse was excised after the incision (width, $>1 \mathrm{~cm}$ ), in order to prevent glabellar ptosis secondary to glabellar myotomy (Figure 6 ). The skin was sutured in two layers of nylon 4.0 (galea and subcutaneous) and poliglecaprone 5.0 (intradermal) (Figure 7).

Dressings were prepared from rectangular foam the size of the frontal region, and elastic bandages were applied (Figure 8) and removed after 24-48 hours.

Revisions were made in 1-2 days; 1 week; and at 1, 3, and 6 months.

\section{RESULTS}

All patients showed good results (Figures 9 to 11), with impediment of frontal (Figures 10, 12 and 13) and glabellar muscles (Figures 14 and 15) during the assessed period, and partial or total improvement of wrinkles and muscle hyperactivity.

Complications included temporary dysesthesia, with paresthesia and pruritus in 8 patients: 3 cases in the central frontal region (supraorbital nerve) and 5 in the parietal region (supraorbital nerve).

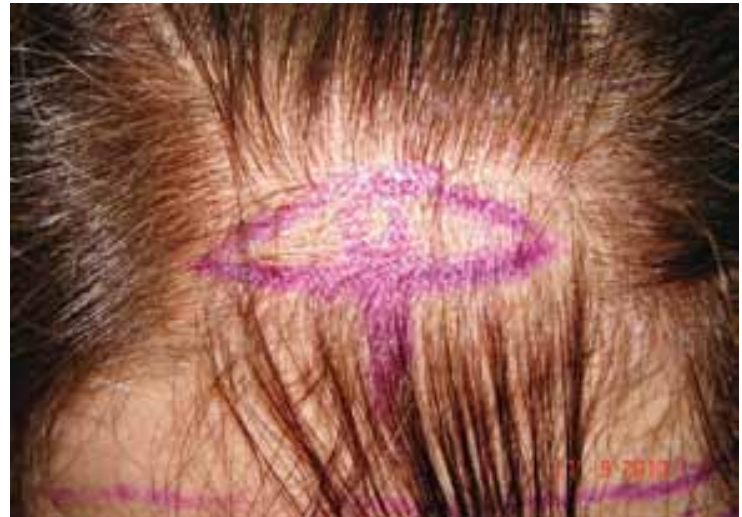

Figure 6 - Skin ellipse to be resected in order to avoid glabellar ptosis.

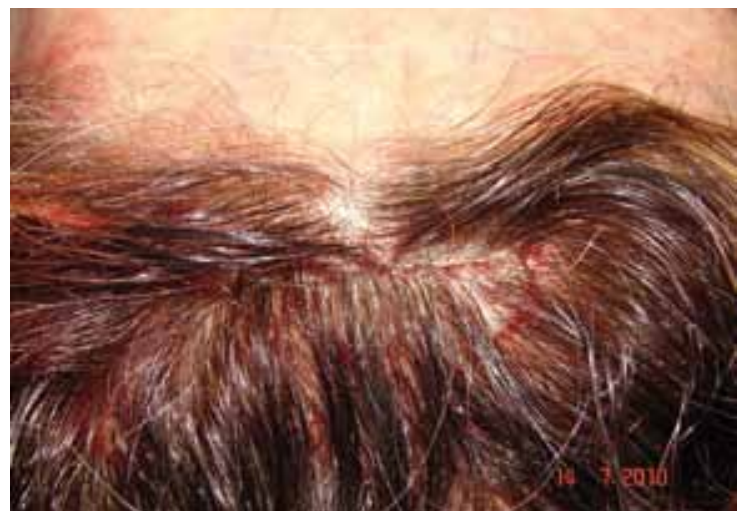

Figure 7-Closing on two levels: appearance at the end of the surgery.
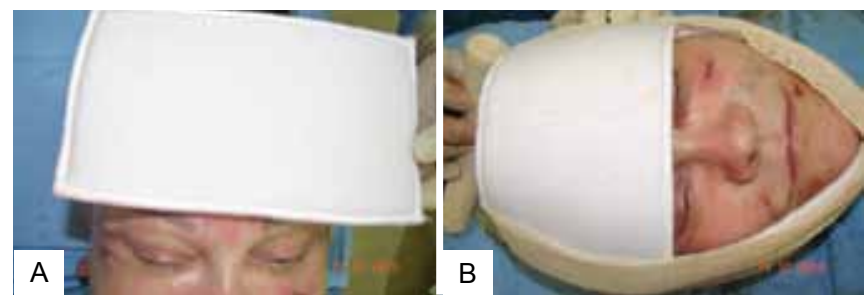

Figure 8 -In A, dressings with rectangular foam, coated with cotton fabric for gentle compression of the frontal region. In

$\boldsymbol{B}$, dressings: fixing the foam with elastic bandages.

Recurrence of muscle contraction occurred in the glabellar region and lateral frontal region in 2 patients, and in the lateral frontal region in only 1 patient. Three patients underwent reoperation using the same approach, up to six months after the first surgery, with total resolution of the problems.

There was one case of seroma; however, hematoma, asymmetry, or infection was not observed in this series of patients.

The quality of scars was deemed good by patients (Figure 16 ), and no dehiscence or alopecia was observed. 

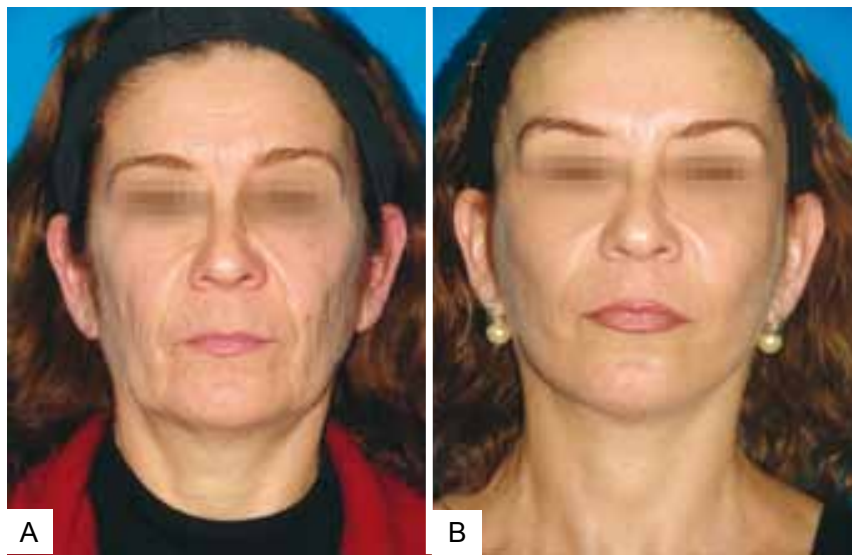

Figure 9 - Case 1. In A, preoperative period: static front view. In $\boldsymbol{B}$, six months after operation: static front view.
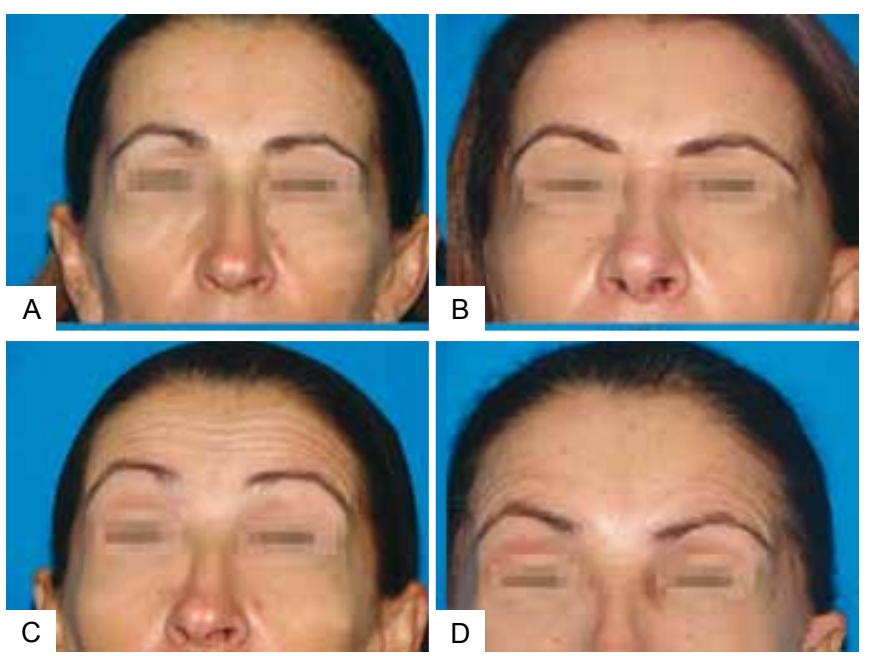

Figure 10 - Case 2. In A, preoperative period: static front view. In $\boldsymbol{B}$, four months after operation: static front view. In $\boldsymbol{C}$, preoperative period: front view during frontal muscle contraction.

In $\boldsymbol{D}$, four months after operation: front view during frontal muscle contraction.

\section{DISCUSSION}

Botulinum toxin is used in many patients for correction of wrinkles and muscle hyperactivity in the frontal and glabellar regions, with good results. After a few applications of botulinum toxin over several years, many of these patients expressed a desire for a longer lasting result. Surgical myotomy and myectomy offer permanent paralysis. Surgical techniques have improved, especially with respect to reduced scarring.

Originally, surgical approaches for treatment of frontal and glabellar muscles were performed exclusively by coronal incision $^{5,6,11}$. Recently ${ }^{7-12}$, blepharoplasty incision ${ }^{13,14}$ and

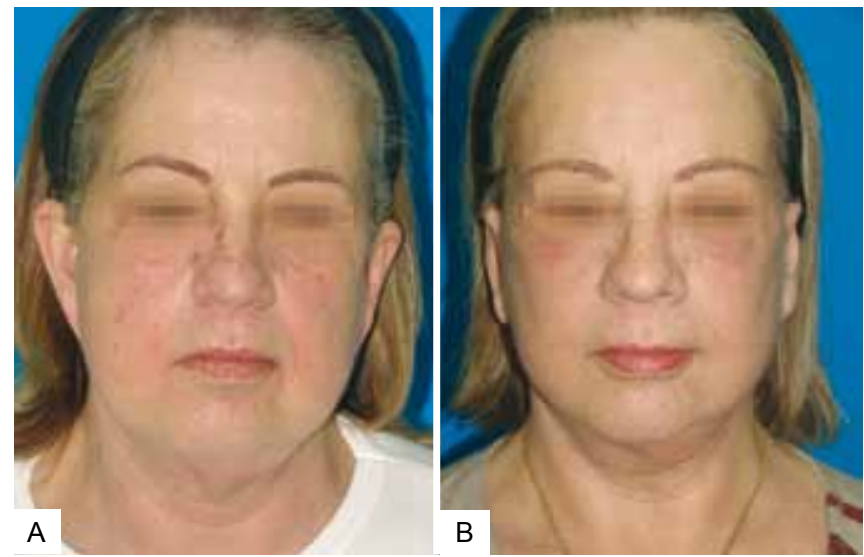

Figure 11 - Case 3. In A, preoperative period: static front view. In $\boldsymbol{B}$, three months after operation: static front view.
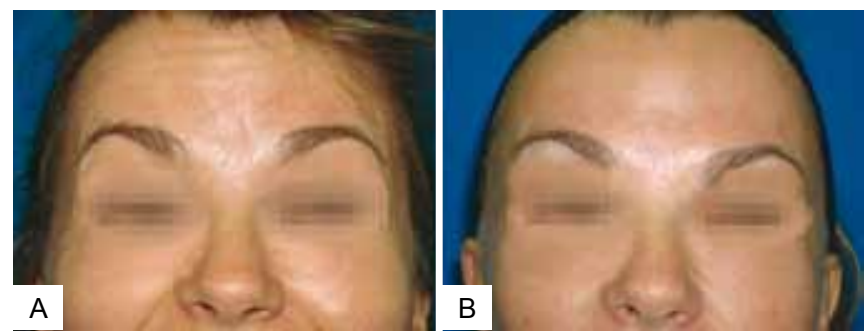

Figure 12 - Case 4. In A, preoperative period: front view in frontal muscles contraction. In $\boldsymbol{B}$, nine months after operation: front view during frontal muscle contraction.

other non-endoscopic approaches have become less invasive alternatives $^{15,16}$.

Advantages of the coronal approach include direct visualization of the frontal and glabellar regions and full treatment of the muscles of both regions. Disadvantages include complications related to long incisions, alopecia, scarring, hematomas, seromas, dysesthesias, and scalp anesthesia. The approach via a small incision on the central frontal scalp avoids long incisions and the associated complications by preserving sensory nerves and their paths. This method ensures better quality of the scar and is performed under direct visualization.

Treatment with the aid of video endoscopic techniques aims to avoid major complications of the coronal approach, and is carried out under indirect visualization. Some papers have reported complications such as asymmetry, eyebrow separation, depression, or excessive elevation ${ }^{12,18,19}$ or complications that may occur with other techniques, depending on the case and the surgical planning (for example, myectomy with depression). Preparation of the video endoscopic equipment and its instruments requires extra surgical time, increasing the risk of contamination. By making a small incision on the central frontal scalp, 

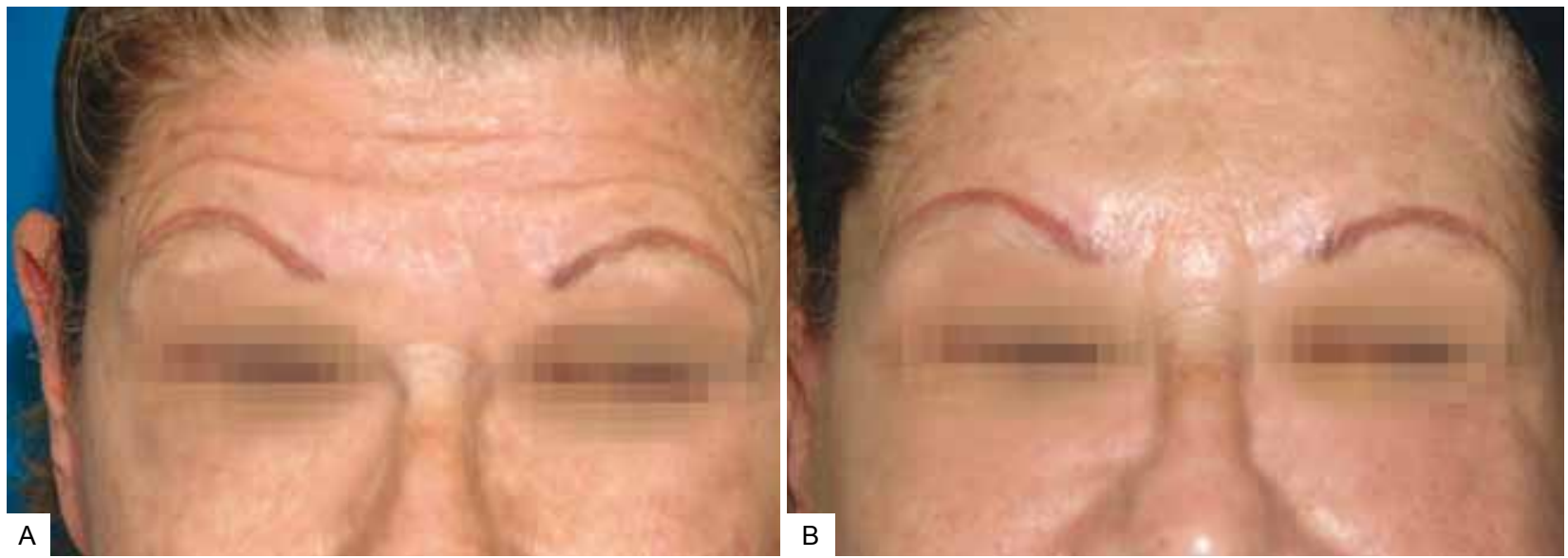

Figure 13 - Case 5. In A, preoperative period: front view during frontal muscle contraction. In $\boldsymbol{B}$, nine months after operation: front view during frontal muscle contraction.
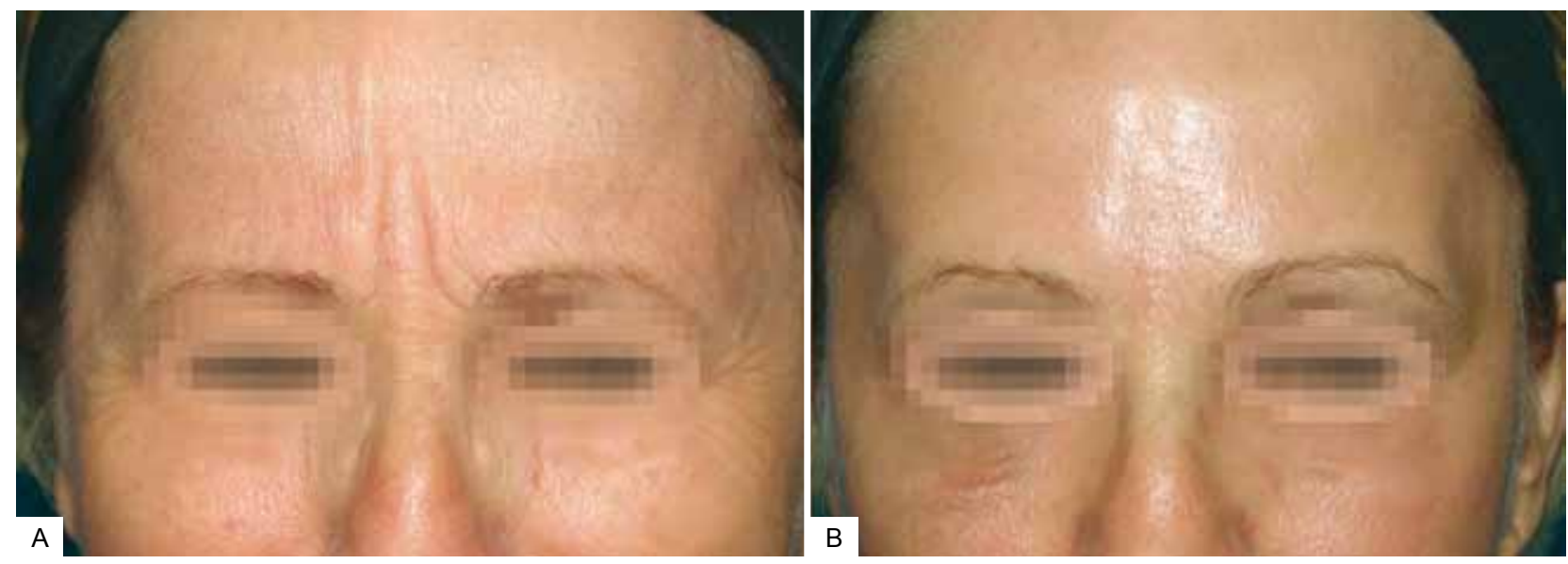

Figure 14 - Case 6. In A, preoperative period: front view in glabellar muscles contraction. In B, one month after operation: front view during glabellar muscle contraction.

frontal and glabellar muscles can be treated in approximately 30 minutes from incision to suture, thus shortening the surgical time, enabling direct visualization and use of conventional surgical instruments, and leaving a single and discreetly positioned scar.

Limited temporal incision is a non-endoscopic alternative to frontal muscle incision, but it does not allow treatment of the glabellar region without the aid of another approach ${ }^{15}$. Pitanguy and Gontijo de Amorim ${ }^{16}$ described a limited bicoronal and juxtaposed incision, using the subperiosteal plane for lifting, which may also be used for myotomy or myectomy. This approach has the disadvantage of blocking the sensory nerves of the scalp, leaving the scar in a more visible position. A small incision on the central frontal scalp seems to be a good alternative in selected cases, since it avoids sectioning of the supraorbital nerve branches, with anatomical preservation of scalp sensitivity.

Despite the preference for a subgaleal dissection plane, a small incision on the central frontal scalp enables the surgeon to access the subperiosteal plane. Accessing the subgaleal plane allows for identification and preservation of the main branches of the supraorbital and supratrochlear nerves. The patients who experienced temporary alteration of sensitivity showed complete improvement or a major improvement in symptoms during the study period. These changes in sensitivity were attributed to perineural edema, dissection, and non-intentional sectioning of small branches. These changes are similar to those observed in dissections of other facial regions undergoing 

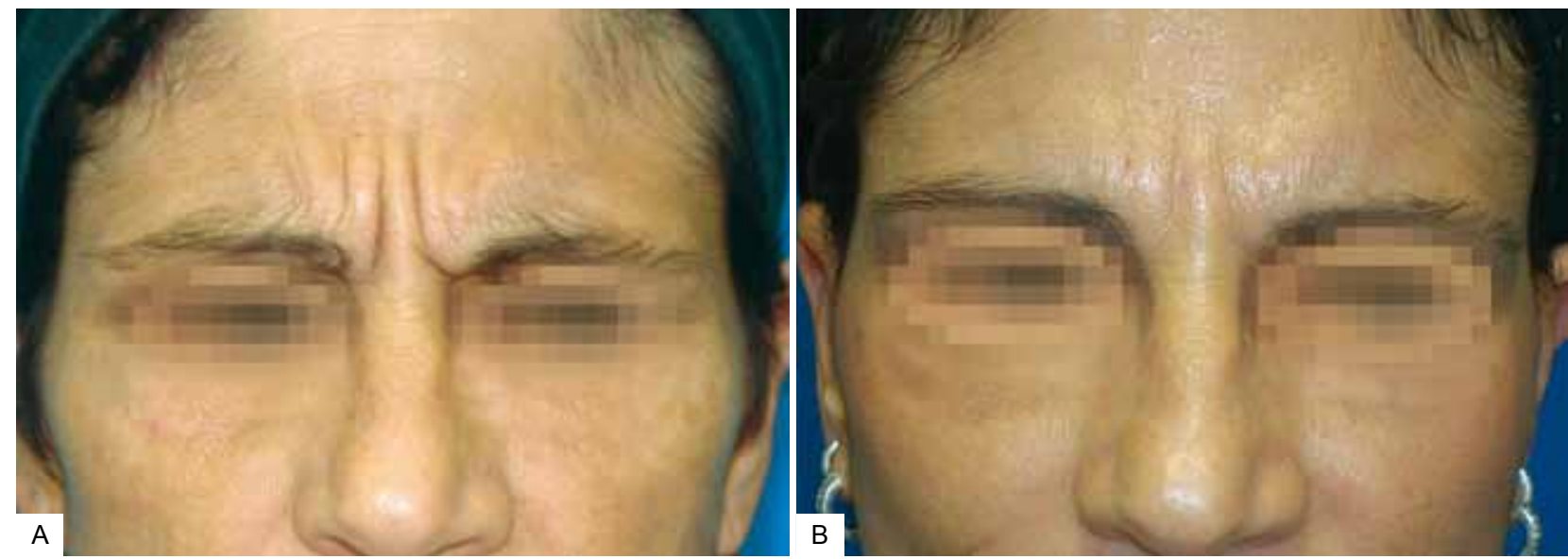

Figure 15 - Case 7. In A, preoperative period: front view during glabellar muscle contraction. In B, seven months after operation: front view during glabellar muscle contraction.
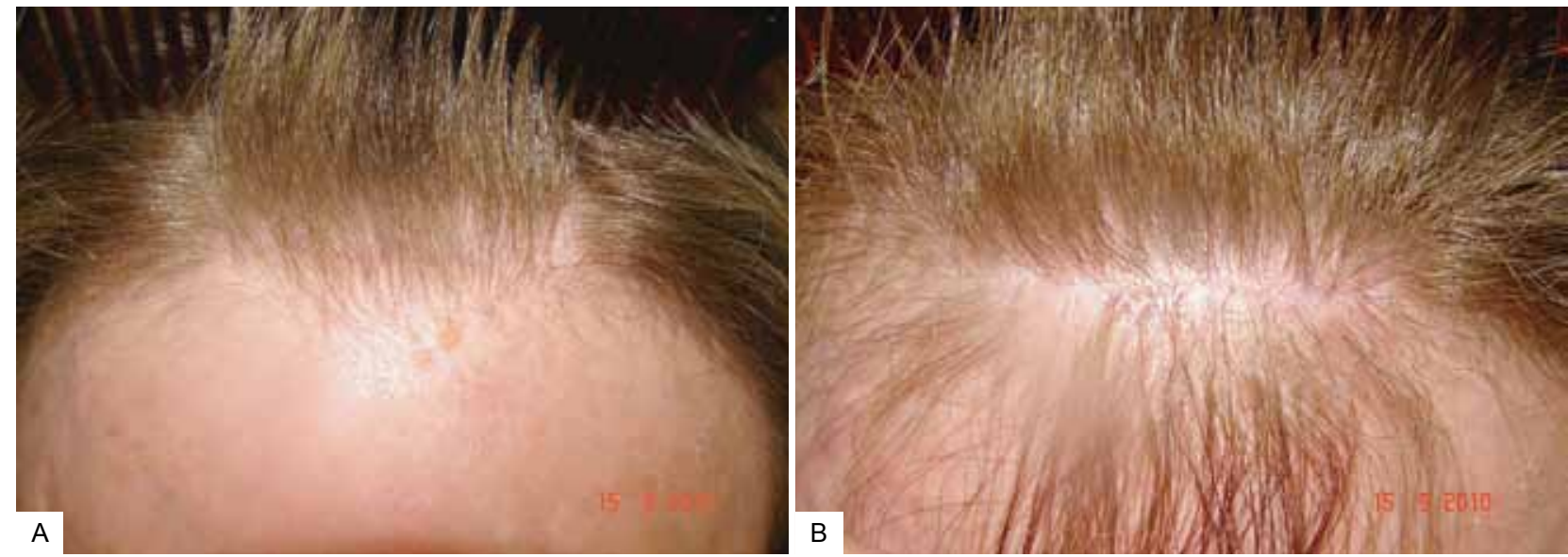

Figure 16-In A, aspect of the scar behind the hair implantation line after one year. In $\boldsymbol{B}$, appearance of the scar in detail after one year.

facial rejuvenation (middle and lower thirds), with temporary changes and complete recovery after a few months. Therefore, with late follow-up, there is a possibility of confirming complete recovery from sensory changes.

In muscle treatment, preference is given to myotomy due to the good results obtained in the last ten years using other approaches, which do not cause depressions or irregularities, thus eliminating the need of grafts. The frontal muscle is divulsed to identify the supraorbital nerve and its main branches. The frontal muscles form a crossover, with the corrugator supercilii muscle serving as a as a reference marker during the procedure. This muscle is isolated by blunt dissection with scissors and is sectioned by electrocautery at two points, medial and lateral to the emergence of the supraorbital nerve, preserving the supratrochlear nerve.

Recurrence of muscle contraction occurred in 2 patients and was located in the lower regions. These patients underwent re-operation within the study period using the same approach of complementary myotomy. The recurrence was attributed to the learning curve associated with the new approach, and could be particularly observed in patients with a long frontal region.

The small incision on the central frontal scalp is completed with the removal of a skin ellipse (width, $>1 \mathrm{~cm}$ ) after the incision in order to avoid secondary glabellar ptosis, which may occur due to incomplete myotomy, especially of the procerus and depressor supercilii muscles.

The dressing, which is important for prevention of seroma and hematoma, should be maintained for 24 to 48 hours. Only one patient took the bandage off before this period and, consequently, suffered seroma.

No similar frontoplasty approaches using a small incision in the central frontal scalp were found in the reviewed literature in MEDLINE and LILACS databases. 


\section{CONCLUSIONS}

For the surgical treatment of wrinkles and muscle hyperactivity, both frontal and glabellar, a small incision on the central frontal scalp seems to be a good alternative to other surgical options, due to the small and discrete scars, in addition to direct visualization of anatomical structures of the frontal and glabellar regions. However, a longer monitoring period is required to consolidate the initial good results.

\section{REFERENCES}

1. Isse NG, Elahi MM. The corrugator supercilii muscle revisited. Aesthet Surg J. 2001;21(3):209-15.

2. Knize DM. Muscles that act on glabellar skin. Plast Reconstr Surg. 2000;105(1):350-61

3. Carruthers JD, Carruthers JA. Treatment of glabellar frown lines with C. botulinum-A exotoxin. J Dermatol Surg Oncol. 1992;18(1):17-21.

4. Fagien S. Botulinum toxin type A for facial aesthetic enhancement: role in facial shaping. Plast Reconstr Surg. 2003;112(5 Suppl):6S-18S

5. Ortiz-Monasterio FB, Barrera G, Olmedo A. The coronal incision in rhytidectomy--the brow lift. Clin Plast Surg. 1978;5(1):167-79.

6. Vinas JC, Caviglia C, Cortinas JL. Forehead rhytidoplasty and brow lifting. Plast Reconstr Surg. 1976;57(4):445-54.

7. Abramo AC. Anatomy of the forehead muscles: the basis for the videoendoscopic approach in forehead rhytidoplasty. Plast Reconstr Surg. 1995;95(7):1170-7.
8. Vasconez LO, Core GB, Gamboa-Bobadilla M, Guzman G, Askren C, Yamamoto Y. Endoscopic techniques in coronal brow lifting. Plast Reconstr Surg. 1994;94(6):788-93.

9. Hamas RS. Reducing the subconscious frown by endoscopic resection of the corrugator muscles. Aesthetic Plast Surg. 1995;19(1):21-5.

10. Abramo AC, Dorta AA. Selective myotomy in forehead endoscopy. Plast Reconstr Surg. 2003;112(3):873-9.

11. Ramirez OM. Why I prefer the endoscopic forehead lift. Plast Reconstr Surg. 1997;100(4):1033-9.

12. De Cordier BC, de la Torre JI, Al-Hakeem MS, Rosenberg LZ, Gardner PM, Costa-Ferreira A, et al. Endoscopic forehead lift: review of technique, cases, and complications. Plast Reconstr Surg. 2002;110(6): 1558-68.

13. Knize DM. Transpalpebral approach to the corrugator supercilii and procerus muscles. Plast Reconstr Surg. 1995;95(1):52-60.

14. Guyuron B, Michelow BJ, Thomas T. Corrugator supercilii muscle resection through blepharoplasty incision. Plast Reconstr Surg. 1995;95(4):691-6.

15. Knize DM. Limited incision foreheadplasty. Plast Reconstr Surg 1999;103(1):271-84.

16. Pitanguy I, Gontijo de Amorim NF. Forehead lifting: the juxtapilose subperiosteal approach. Aesthetic Plast Surg. 2003;27 (1):58-62.

17. Lemperle G, Holmes RE, Cohen SR, Lemperle SM. A classification of facial wrinkles. Plast Reconstr Surg. 2001;108(6):1735-50.

18. Chiu ES, Baker DC. Endoscopic brow lift: a retrospective review of 628 consecutive cases over 5 years. Plast Reconstr Surg. 2003;112(2):628-33

19. Guyuron B. Endoscopic forehead rejuvenation: I. Limitations, flaws, and rewards. Plast Reconstr Surg. 2006;117(4):1121-33.

\section{Correspondence to:}

Rogério Schutzler Gomes

Av. Osvaldo Rodrigues Cabral, 1570 - sala 302 - Centro - Florianópolis, SC, Brazil - CEP 88015-710

E-mail:rogerio@rogeriogomes.com.br 